\title{
EDITORIAL
}

\section{Significance of emphysema observed on computed tomography scan in asthma}

\author{
F. Paganin*+, D. Jaffuel*, J. Bousquet*
}

\begin{abstract}
Computed tomography (CT) scan has been used in the diagnosis of airways diseases [1] because of the high degree of anatomical detail provided. Most abnormalities, such as bronchiectasis and emphysema, seen on a CT scan have been anatomically validated, but their clinical significance is not always fully understood. Highresolution CT (HR-CT) has been used to study asthmatics [2-8]. It has been consistently observed that more abnormalities related to fixed airways remodelling, such as bronchial dilatation and bronchiectasis are observed in asthmatic subjects than in normal subjects, although the clinical consequences of these findings are not clear. HRCT scans have also been used to measure the internal size of the airways at baseline, during challenge or after bronchodilatation [9-12]. However, there is no data on lung density in patients with acute and chronic asthma. This was the aim of the paper published in the present issue of the European Respiratory Journal [13].

The relationship between asthma and emphysema was suggested in 1952 by RoYle [14] who found emphysema in patients with severe asthma. However, the study was flawed since chest radiographs failed to recognize mild emphysema [15] and most of the patients studied were current or exsmokers.
\end{abstract}

\section{Importance of CT scan in the diagnosis of emphysema}

Pulmonary emphysema is a pathological diagnosis, but correlations between results of lung function tests and the extent of emphysema are poor. Lung function tests are also nonspecific for emphysema, and alteration of transfer factor of the lung for carbon monoxide $(T \mathrm{~L}, \mathrm{CO})$ may be due to cardiogenic oedema or interstitial disease. The diagnosis of pulmonary emphysema can be made with relative confidence on the basis of clinical and radiological criteria. Despite the fact that very mild emphysema goes undetected and the severity of the disease may be underestimated, HR-CT is the most sensitive radiographic method with which to image emphysema and has been shown to be more sensitive than pulmonary function tests or TL,CO [15-18]. Many studies have demonstrated significant correlations between CT scan data and pathological observations of lungs obtained at autopsy or after surgery for both centrilobular and panacinar emphysema [19-23]. However, occasionally CT scans give false-positive findings and the criteria used

*Service des Maladies Respiratoires and INSERM U454 Hôpital Arnaud de Villeneuve. 34295 Montpellier, France. ${ }^{+}$Service de Réanimation, Saint-Denis de la Réunion, France. to assess overinflation are sensitive but not specific. The presence and extent of emphysema can be determined by visual assessment of areas of abnormally low attenuation or by objective quantification based on the attenuation values.

HR-CT scans at $1 \mathrm{~cm}$ intervals were studied to determine whether the relative area of lung occupied by attenuation values lower than a given threshold could be used as an indication of emphysema [24]. The strongest correlation was found for -950 Hounsfield units (HU). The study also revealed that the TL,CO associated with HRCT quantification is sufficient to predict microscopic measurements. A subsequent study from the same group suggests that HR-CT lung densitometry is also influenced by total lung capacity and, to lesser degree, by age [25]. Normal CT attenuation values for the lung have not yet been established. Millimetric slices are more accurate than centrimetric ones in the diagnosis of emphysema but not all studies found a major difference between both [23]. Recently, newer techniques of CT scan such as the sliding thin slab, minimum intensity projection (STS-MIP) have been implemented to improve the accuracy of CT scans [26]. CT scans performed at full expiration can reveal emphysema not detected by conventional HR technique at full inspiration [27]. However, care must be taken as the images observed in full expiration which are not visible at full inspiration may reflect air trapping rather than true emphysema [24]. These results were subsequently confirmed in asthmatics [28].

\section{Demonstration of emphysema and bronchiectasis using CT-scan in asthma}

The major message of the paper published in this issue of the journal [13] is that at least some patients with chronic, stable asthma develop a reduced CT lung density similar to that in patients with emphysema. A group of asthmatics of variable severity was compared to healthy subjects and patients with chronic bronchitis and airflow limitation, hereafter referred to as COPD. Several techniques have been used in performing CT scans. BIERNACKI et al. [13] used a validated method of CT scan but they studied centimetric slices. This method is acceptable for the assessment of emphysema although less sensitive than the sliding thin slab projection technique [26]. The authors found that both asthmatics and COPD patients had a lower lung density than normal healthy subjects. Moreover, COPD patients had a lower lung density than asthmatics, but there was an overlap between the two groups. Unfortunately, in the study, all 
the asthmatics were considered together although forced expiratory volume in one second (FEV1) levels ranged $33-105 \%$ of predicted values. It is possible that there is a significant correlation between lung density and the severity of asthma, since it has been shown that CT scan scores are associated with the severity of the disease [4].

Using HR-CT scans, PAGANIN et al. [3] found emphysema-like images in $18 \%$ of asthmatics. These remained unchanged after treatment. In a larger study carried out in 126 asthmatics, PAGANIN et al. [4] found $39.3 \%$ of emphysema-like images which, interestingly, were correlated with the severity of asthma. In another study, emphysema-like images were observed in 19\% of asthmatics and correlated with FEV1, TL,CO and functional residual capacity [29]. However, this study was flawed since $36 \%$ of asthmatics were current or exsmokers, and a very heterogeneous group of asthmatics was studied, some patients receiving oral corticosteroids, and this was not taken into account. Emphysema-like images were observed in $53 \%$ of patients with allergic bronchopulmonary aspergillosis (ABPA) and in 9\% of asthmatics without ABPA [5]. PARK et al. [8] found mosaic lung attenuation which was correlated with airflow obstruction in $18 \%$ of asthmatics. Air trapping was observed in $50 \%$ of asthmatics but was not correlated with airflow obstruction and the predicted residual volume, but was a more frequent finding in expiratory CT scans of asthmatic patients compared with control subjects. Finally, GRENIER et al. [7] observed decreased lung attenuation in $31 \%$ of asthmatics and in $7 \%$ of healthy subjects. These studies suggest that emphysema may be present in a subset of asthmatics.

Low CT lung density may also result from air trapping and it may be difficult to differentiate between this and true emphysema in asthmatics. Dead space and expiratory volumes are increased during acute asthma exacerbation but these physiological findings may be difficult to assess in patients with chronic stable asthma. LYNCH et al. [29] considered the emphysema-like images they observed in asthmatics as air trapping. However, such an interpretation is in contrast with studies which compared CT scan results using the full inspiration technique and pathological data in emphysema [19-23].

TL,CO may be used to differentiate between air trapping and emphysema in asthmatics. BIERNACKI et al. [13] have shown that TL,CO was significantly lower in patients with COPD than in asthmatics, although seven of the 17 asthmatics had a low TL,CO. The same authors have previously found that measurements of CT lung density correlate with morphometric measurements of the size of distal airspaces [30]. TL,CO appears to be the lung function parameter which best correlates with structure/function studies in emphysema $[31,32]$ and has also been shown to correlate with CT lung density in COPD [33]. In the papers from BIERNACKI et al. [13] and PAGANIN et al. [3], CT scans were carried out before and after treatment and emphysema-like images were found to be fixed abnormalities. These studies suggest therefore that at least some patients may have true emphysema.

A secondary end-point of the paper published in this issue of the journal [13] was the assessment of bronchiectasis. It is not surprising that they did not find such lesions because millimetric slices are far more discerning than centimetric ones for such a study [34, 35].
Bronchiectases have been observed in asthma when millimetric slices were studied $[3-5,7,8]$ but not when centrimetric slices were assessed [36].

\section{Significance of emphysema using CT scan in asthma}

In the pathological examination of asthmatic lungs, true emphysema, a destructive process focusing on the acinus, was observed in some cases [37-39]. This is not a common feature [40] and is never extensive. Moreover, in most of the patients studied, smoking habits were not assessed so it is not fully clear whether the emphysema was really due to asthma. In the study by SoBonya [37] one out of seven nonsmoking asthmatics showed histological features of mild emphysema. Parenchymal destruction has been observed in a fatal case of a nonsmoking asthmatic with a toluene di-isocyanate sensitivity [41], however, the mechanisms of this occupational form of asthma may differ from other forms of the disease.

Bronchial gland duct ectasia has been described in fatal bronchial asthma [40, 42] and was associated with emphysema. The histological features of patients in whom death was considered to be due to asthma were studied [43]. Bronchial gland duct ectasia was diagnosed if there was more than one abnormally dilated epithelial lined protrusion from a bronchus, extending through the smooth muscle layer. Interstitial emphysema was present in 10 of 53 clinical cases of fatal asthma, all of whom had bronchial gland duct ectasia and a histological diagnosis of asthma. Interstitial emphysema was not observed in control subjects. The authors concluded that bronchial gland duct ectasia is a common histological feature of severe asthma, and that interstitial emphysema may be a consequence of rupture of these dilated gland ducts. However, the relationship between these histological features and CT scan emphysema-like images are unknown.

In conclusion, using computed tomography scans, emphysema-like changes may be observed in a subset of nonsmoking asthmatics. Emphysema is unlikely to be due to alveolar disruption but rather to an extensive peribronchial fibrosis or a rupture of dilated bronchial glands and may therefore, relate to cicatricial emphysema. Although such studies are difficult to perform we need to compare computed tomography scan results and pathological data in asthma to assess the extent of emphysema.

\section{References}

1. Grenier P, Cordeau MP, Beigelman C. High-resolution computed tomography of the airways. J Thorac Imaging 1993; 8: 213-229.

2. Neeld DA, Goodman LR, Gurney JW, Greenberger PA, Fink JN. Computerized tomography in the evaluation of allergic bronchopulmonary aspergillosis. Am Rev Respir Dis 1990; 142: 1200-1205.

3. Paganin F, Trussard V, Seneterre E, et al. Chest radiography and high resolution computed tomography of the lungs in asthma. Am Rev Respir Dis 1992; 146: 1084-1087.

4. Paganin F, Seneterre E, Chanez P, et al. Computed tomography of the lungs in asthma: influence of disease severity and etiology. Am J Respir Crit Care Med 1996; 153: $110-114$. 
5. Angus RM, Davies ML, Cowan MD, McSharry C, Thomson NC. Computed tomographic scanning of the lung in patients with allergic bronchopulmonary aspergillosis and in asthmatic patients with a positive skin test to Aspergillus fumigatus. Thorax 1994; 49: 586-589.

6. Boulet L, Belanger M, Carrier G. Airway responsiveness and bronchial-wall thickness in asthma with or without fixed airflow obstruction. Am J Respir Crit Care Med 1995; 152: 865-871.

7. Grenier P, Mourey-Gerosa I, Benali K, et al. Abnormalities of the airways and lung parenchyma in asthmatics: CT observations in 50 patients and inter- and intraobserver variability. Eur Radiol 1996; 6: 199-206.

8. Park CS, Muller NL, Worthy SA, Kim JS, Awadh N, Fitzgerald M. Airway obstruction in asthmatic and healthy individuals: inspiratory and expiratory thin-section CT findings. Radiology 1997; 203: 361-367.

9. Seneterre E, Paganin F, Bruel JM, Michel FB, Bousquet $\mathrm{J}$. Measurement of the internal size of bronchi using high resolution computed tomography (HRCT). Eur Respir J 1994; 7: 596-600.

10. Kim SJ, Im JG, Kim IO, et al. Normal bronchial and pulmonary arterial diameters measured by thin section CT. J Comput Assist Tomogr 1995; 19: 365-369.

11. Okazawa M, Muller N, McNamara AE, Child S, Verburgt L, Pare PD. Human airway narrowing measured using high resolution computed tomography. Am J Respir Crit Care Med 1996; 154: 1557-1562.

12. Forkert L, Watanabe H, Sutherland K, Vincent S, Fisher JT. Quantitative videobronchoscopy: a new technique to assess airway caliber. Am J Respir Crit Care Med 1996; 154: 1794-1803.

13. Biernacki W, Redpath A, Best J, MacNee W. Measurement of CT lung density in patients with chronic asthma. Eur Respir J 1997; 10: 2455-2459.

14. Royle X. X-ray appearances in asthma. Br Med J 1952; i: $577-580$.

15. Klein JS, Gamsu G, Webb WR, Golden JA, Muller NL. High-resolution CT diagnosis of emphysema in symptomatic patients with normal chest radiographs and isolated low diffusing capacity. Radiology 1992; 182: 817-821.

16. Gurney JW. The pathophysiology of airways disease. $J$ Thorac Imaging 1995; 10: 227-235.

17. Stern EJ, Song JK, Frank MS. CT of the lungs in patients with pulmonary emphysema. Semin Ultrasound CTMR 1995; 16: 345-352.

18. Thurlbeck WM, Muller NL. Emphysema: definition, imaging, and quantification. Am J Roentgenol 1994; 163 : 1017-1025.

19. Bergin CJ, Muller NL, Miller RR. CT in the qualitative assessment of emphysema. J Thorac Imaging 1986; 1 : 94-103.

20. Bergin C, Muller N, Nichols DM, et al. The diagnosis of emphysema. A computed tomographic-pathologic correlation. Am Rev Respir Dis 1986; 133: 541-546.

21. Murata K, Itoh H, Todo G, et al. Centrilobular lesions of the lung: demonstration by high-resolution CT and pathologic correlation. Radiology 1986; 161: 641-645.

22. Hruban RH, Meziane MA, Zerhouni EA, et al. High resolution computed tomography of inflation-fixed lungs. Pathologic-radiologic correlation of centrilobular emphysema. Am Rev Respir Dis 1987; 136: 935-940.

23. Kuwano K, Matsuba K, Ikeda T, et al. The diagnosis of mild emphysema. Correlation of computed tomography and pathology scores. Am Rev Respir Dis 1990; 141: 169-178.

24. Gevenois PA, De-Vuyst P, de-Maertelaer V, et al. Comparison of computed density and microscopic mor- phometry in pulmonary emphysema. Am J Respir Crit Care Med 1996; 154: 187-192.

25. Gevenois PA, Scillia P, de-Maertelaer V, Michils A, De-Vuyst P, Yernault JC. The effects of age, sex, lung size, and hyperinflation on CT lung densitometry. Am J Roentgenol 1996; 167: 1169-1173.

26. Remy-Jardin M, Remy J, Gosselin B, Copin MC, Wurtz A, Duhamel A. Sliding thin slab, minimum intensity projection technique in the diagnosis of emphysema: histopathologic-CT correlation. Radiology 1996; 200: 665-671.

27. Miniati M, Filippi E, Falaschi F, et al. Radiologic evaluation of emphysema in patients with chronic obstructive pulmonary disease. Chest radiography versus high resolution computed tomography. Am J Respir Crit Care Med 1995; 151: 1359-1367.

28. Newman KB, Lynch DA, Newman LS, Ellegood D, Newell J Jr. Quantitative computed tomography detects air trapping due to asthma. Chest 1994; 106: 105-109.

29. Lynch DA, Newell JD, Tschomper BA, Cink TM, Newman LS, Bethel R. Uncomplicated asthma in adults: comparison of CT appearance of the lungs in asthmatic and healthy subjects. Radiology 1993; 188: 829-833.

30. Gould GA, MacNee W, McLean A, et al. CT measurements of lung density in life can quantitate distal airspace enlargement - an essential defining feature of human emphysema. Am Rev Respir Dis 1988; 137: 380-392.

31. Berend N, Woolcock AJ, Marlin GE. Correlation between the function and structure of the lung in smokers. Am Rev Respir Dis 1979; 119: 695-705.

32. Petty TL, Silvers GW, Stanford RE. Functional correlations with mild and moderate emphysema in excised human lungs. Am Rev Respir Dis 1981; 124: 700-704.

33. Gould GA, Redpath AT, Ryan M, et al. Lung CT density correlates with measurements of airflow limitation and the diffusing capacity. Eur Respir J 1991; 4: 141-146.

34. Grenier P, Maurice F, Musset D, Menu Y, Nahum H. Bronchiectasis: assessment by thin-section CT. Radiology 1986; 161: 95-99.

35. Primack SL, Remy-Jardin M, Remy J, Muller NL. Highresolution CT of the lung: pitfalls in the diagnosis of infiltrative lung disease. Am J Roentgenol 1996; 167: 413-418.

36. Kinsella M, Muller NL, Staples C, Vedal S, Chan-Yeung M. Hyperinflation in asthma and emphysema. Assessment by pulmonary function testing and computed tomography. Chest 1988; 94: 286-289.

37. Sobonya RE. Quantitative structural alterations in longstanding allergic asthma. Am Rev Respir Dis 1984; 130: 289-292.

38. Messer J, Peters G, Bennett W. Causes of deaths and pathological findings in 304 cases of bronchial asthma. Chest 1960; 38: 616-624.

39. Houston J, de-Nevasquez S, Trounce J. A clinical and pathological study of fatal cases of status asthmaticus. Thorax 1953; 8: 207-213.

40. Dunnill M, Massarella G, Anderson J. C omparison of the quantitative anatomy of the bronchi in normal subjects, in status asthmaticus, in chronic bronchitis, and in emphysema. Thorax 1969; 24: 176-179.

41. Fabbri LM, Danieli D, Crescioli S, et al. Fatal asthma in a subject sensitized to toluene diisocyanate. Am Rev Respir Dis 1988; 137: 1494-1498.

42. Huber H, Koessler K. The pathology of bronchial asthma. Arch Intern Med 1922; 30: 689-696.

43. Cluroe A, Holloway L, Thomson K, Purdie G, Beasley R. Bronchial gland duct ectasia in fatal bronchial asthma: association with interstitial emphysema. J Clin Pathol 1989; 42: 1026-1031. 